\title{
Emergency peripartum hysterectomy: a 3 year review at a tertiary care hospital in Vindhya region of India
}

\author{
Neha Khatik', Avani Pandey ${ }^{1 *}$, Shabd Singh Yadav², Kalpana Yadav ${ }^{1}$
}

\begin{abstract}
${ }^{1}$ Department of Obstetrics and Gynecology, ${ }^{2}$ Department of Pediatrics, Shyam Shah Medical College and Sanjay Gandhi Hospital, Rewa, Madhya Pradesh, India
\end{abstract}

Received: 31 July 2020

Revised: 07 September 2020

Accepted: 08 September 2020

\author{
*Correspondence: \\ Dr. Avani Pandey, \\ E-mail: avanipandey850@gmail.com
}

Copyright: (c) the author(s), publisher and licensee Medip Academy. This is an open-access article distributed under the terms of the Creative Commons Attribution Non-Commercial License, which permits unrestricted non-commercial use, distribution, and reproduction in any medium, provided the original work is properly cited.

\begin{abstract}
Background: Emergency peripartum hysterectomy (EPH), although rare in modern obstetric, still performed as lifesaving surgical procedure to control haemorrhage that is unresponsive to conservative treatment. The objective of this study was to review the incidence, indications, and predisposing factors and associated complications of EPH.

Methods: The present study is a retrospective study included 37 women who underwent EPH over a period of 3 year. The records were collected from medical record department.

Results: 37 patients underwent EPH during this period making an incidence of 1.1 per 1000 deliveries. Most common indication of EPH in present study was morbidly adherent placenta (MAP) seen in 19 cases (51.4\%). 36 patients (97.4\%) patient underwent cesarean section at the time of their index pregnancy and 25 out of $37(67.6 \%)$ patient had undergone prior cesarean delivery. 20 (54\%) patients underwent total abdominal hysterectomy (TAH) and 17 (46\%) patients underwent subtotal hysterectomy (STH). Mean operative time, estimated blood loss, injury to urinary tract, febrile illness and duration of hospital stay was higher in TAH group as compared to STH group but difference was not statistically significant except for estimated blood loss. Maternal mortality was seen in $20 \%$ of cases and neonatal mortality was seen in $56.8 \%$ of cases.

Conclusions: EPH although lifesaving but have devastating consequences. EPH should be performed with a multidisciplinary team approach. Measures should be taken to reduce caesarean section rate.
\end{abstract}

Keywords: Emergency peripartum hysterectomy, Postpartum hemorrhage, Morbidly adherent placenta, Total abdominal hysterectomy, Sub-total hysterectomy

\section{INTRODUCTION}

Postpartum hemorrhage (PPH) is one of the leading causes of maternal mortality and morbidity. Although maternal mortality rates have declined greatly in the developed countries, PPH still remains a major contributor to maternal deaths in developing countries.

According to sample registration system 2015-2017, the maternal mortality rate of India was $122 / 100000$ live births and a decline of $6.2 \%$ was observed during this period. ${ }^{1}$
Most maternal deaths were attributed to direct obstetric causes like PPH, pregnancy induced hypertension and septicaemia.

Emergency peripartum hysterectomy (EPH), although rare in modern obstetrics, is still performed as a lifesaving surgical procedure to control haemorrhage that is unresponsive to conservative treatment.

The wide range of variation in the incidence of $\mathrm{EPH}$ in different part of world suggest that its incidence depends upon standard of antenatal care, effectiveness of family 
planning services and availability of various modern obstetric services like uterine artery embolisation of a given community. ${ }^{2}$ Illiteracy, poverty, poor antenatal care, delivery by unskilled birth attendants, poor transportation facilities, inadequate distribution of health services and delay in seeking healthcare facilities are responsible for high incidence of EPH in developing nation.

Indications for peripartum hysterectomy have changed throughout the years. In the past, the most common indications were uterine atony and uterine rupture. , $^{3,4}$ Recent studies list placenta accreta as the most common indication especially in the developed countries due to an increase in the caesarean delivery rate..$^{5,6}$

In spite of being a lifesaving procedure, EPH is known to be associated with uncontrolled bleeding, blood transfusion risks, infection, disseminated intravascular coagulation (DIC) and high maternal mortality and morbidity. This procedure can be traumatic for some couples as it inevitably sacrifices women's child bearing capacity. In face of uncontrolled hemorrhage, the decision to perform procedure or delay while attempting other conservative measures require good clinical judgement. It should remain a last resort after other measures have been failed.

A near miss event is defined as a woman who nearly died but survived a complication that occurred during pregnancy, childbirth, or within 42 days of termination of pregnancy. ${ }^{7} \mathrm{EPH}$ can be appropriately classified as a near miss event and study of such events provide an insight into the standard of care provided and help to reduce maternal morbidity and mortality.

With this background this study is planned to assess and evaluate the demographic profile and indication, operative details, maternal morbidity and mortality and neonatal outcome in women undergoing EPH.

Aims and objectives were to assess incidence, demographic profile, indications, complications, operative details; to determine the maternal and fetal outcome of peripartum hysterectomies; and to compare total versus subtotal hysterectomy (STH).

\section{METHODS}

The present study is a retrospective study which was conducted in the department of obstetrics and gynaecology, Shyam Shah medical college, Rewa. This study included all women who underwent EPH over a period of 3 year from April 2017 to March 2020. The records were collected from the medical record department. The case file were reviewed regarding demographic profile of women, previous obstetrics history, details of current pregnancy and delivery, type and indication of peripartum hysterectomy, outcomes of hysterectomy as intraoperative and postoperative complications, length of hospital stay, amount of blood transfused, neonatal outcome, maternal morbidity and mortality. Ethical approval for the study was obtained from the institute ethical committee. Data was entered in Microsoft Excel spreadsheet and analyzed using statistical package for the social sciences (SPSS) software version 22.0. For categorical variables, data was compiled as frequency and percent. For continuous variables, data was calculated as mean \pm standard deviation (SD).

\section{Inclusion criteria}

Patients who underwent peripartum hysterectomy either immediately or within forty-two days of vaginal or cesarean delivery.

Peripartum hysterectomy performed after 24 weeks of gestational age.

\section{Exclusion criteria}

Cases of hysterectomy performed before 24 weeks of gestational age.

Hysterectomy performed for any gynecological condition like leiomyomas and carcinoma cervix.

\section{RESULTS}

During the three- year study period, there were a total of 31,457 deliveries occurred in our institution out of which 24,862 were vaginal deliveries and 6,687 were cesarean sections. 37 patients underwent EPH during this period making an incidence of 1.1 per 1000 deliveries. The rate of EPH was 5.2 per 1,000 cesarean section deliveries and 0.04 per 1,000 vaginal deliveries (Table 1).

Table 1: Incidence of emergency peripartum hysterectomy.

\begin{tabular}{|l|l|}
\hline Statistical data & Number \\
\hline Total number of deliveries & 31,457 \\
\hline Number of caesareans & 6,687 \\
\hline Number of vaginal deliveries & 24,862 \\
\hline Number of peripartum hysterectomy & 37 \\
\hline Incidence of peripartum hysterectomy & $1.1 / 1000$ \\
\hline $\begin{array}{l}\text { Incidence of peripatum hysterectomy } \\
\text { following caesarean }\end{array}$ & $5.2 / 1000$ \\
\hline $\begin{array}{l}\text { Incidence of peripatum hysterectomy } \\
\text { following vaginal deliveries }\end{array}$ & $0.04 / 1000$ \\
\hline
\end{tabular}

Demographic details associated with EPH are shown in Table 2 and 3.The study included $28(75.7 \%)$ women who were above the age of 25 years. 18 women were second gravida, 2 were grand multigravida and 10 were primigravida.

The operative notes and histopathology reports were used to determine the cause of EPH. Most common indication of EPH in present study was morbidly adherent placenta 
(MAP) seen in 19 cases (51.4\%). Next common indication was rupture of unscarred uterus in 8 cases $(21.6 \%)$ followed by rupture of scarred uterus in 7 cases $(18.9 \%)$ and uterine atony in 3 cases (8\%). The indications for EPH are listed in Table 4.

Table 2: Distribution of age in study population.

\begin{tabular}{|ll|}
\hline Age (years) & No. of women (\%) \\
\hline $\mathbf{2 0}$ & $0(0)$ \\
\hline $\mathbf{2 0 - 2 5}$ & $9(24.3)$ \\
\hline $\mathbf{2 6 - 3 0}$ & $20(54.1)$ \\
\hline $\mathbf{3 1 - 3 5}$ & $8(21.6)$ \\
\hline Total & $37(100)$ \\
\hline
\end{tabular}

Table 3: Distribution of parity in study population.

\begin{tabular}{|ll|}
\hline Parity & Number \\
\hline P1 & 10 \\
\hline P2 & 18 \\
\hline P3 & 4 \\
\hline P4 & 3 \\
\hline$>$ P5 & 2 \\
\hline Total & 37 \\
\hline
\end{tabular}

Table 4: Indication of emergency hysterectomy in study population.

\begin{tabular}{|lll|}
\hline Indication & Number & $\%(\mathbf{N}=\mathbf{3 7})$ \\
\hline MAP & 19 & \\
\hline Scarred uterus & 16 & 43.2 \\
\hline Unscarred uterus & 3 & 8.1 \\
\hline Rupture uterus & 15 & \\
\hline Scarred uterus & 7 & 18.9 \\
\hline Unscarred uterus & 8 & 21.6 \\
\hline Atonic PPH & 3 & 8.1 \\
\hline
\end{tabular}

The analysis of risk factors showed that 36 patients $(97.4 \%)$ underwent cesarean section at the time of their index pregnancy. 6 out of $36(16.7 \%)$ patients underwent elective section and 30 patients underwent emergency cesarean delivery. In our study, all cases of uterine rupture were found ruptured at the time of admission and 25 out of $37(67.6 \%)$ patients had undergone prior cesarean delivery. 12 out of $25(48 \%)$ of them had one prior section and 12 $(48 \%)$ had two prior sections and $1(4 \%)$ patient had prior three sections. 19 patients $(51.3 \%)$ had placenta accreta and 16 patients $(43.2 \%)$ was having placenta previa. 2 patients $(5.4 \%)$ had parity $\geq \mathrm{P} 5$. Previous curettage was present in 5 out of 37 patients $(13.5 \%) .2$ patients $(5.4 \%)$ had twin vaginal delivery (Table 5).

The prevalence of placenta accrete was 64, 60 and 100\% for those with 1,2, and 3 or more prior cesarean deliveries, respectively, with a $\mathrm{p}$ value of 0.049 . For placenta previa, it was found that the percentages were 66,50 , and $0 \%$ for 1,2 , and 3 or more prior cesarean deliveries, respectively, with a $\mathrm{p}$ value of 0.09 . Moreover, further analysis showed that 14 patients $(73 \%)$ of placenta accreta underwent prior cesarean section and had placenta previa, 2 patients had placenta previa only and 3 patients had a history of instrumentation in uterine cavity and did not present placenta previa.

$20(54 \%)$ patients underwent total abdominal hysterectomy (TAH) and $17(46 \%)$ patients underwent STH. 13 out of 19 (68.4\%) patients of morbidly adherent placenta underwent $\mathrm{TAH}$ and 6 (31.6\%) patients underwent STH. In case of rupture uterus 6 out of 15 $(40 \%)$ and $9(60 \%)$ patients underwent STH. And out of 3 cases of atonic PPH, 1 (33.3\%) had TAH and 2 (66.7\%) patients had STH. Table 6 illustrates the type of hysterectomy according to indications.

Table 5: Analysis of risk factors of emergency hysterectomy.

\begin{tabular}{|c|c|c|}
\hline Risk factor & No. of EPH & $\%$ \\
\hline $\begin{array}{l}\text { Cesarean section in index } \\
\text { pregnancy }\end{array}$ & 36 & 97.3 \\
\hline \multicolumn{3}{|l|}{ Prior cesarean delivery } \\
\hline No cesarean section & 12 & 32.4 \\
\hline One cesarean section & 14 & 37.8 \\
\hline Two cesarean section & 10 & 27 \\
\hline Three cesarean section & 1 & 2.7 \\
\hline \multicolumn{3}{|l|}{ Accreta } \\
\hline Yes & 19 & 51.3 \\
\hline No & 18 & 48.6 \\
\hline \multicolumn{3}{|l|}{ Previa } \\
\hline Yes & 16 & 43.2 \\
\hline No & 21 & 56.7 \\
\hline \multicolumn{3}{|l|}{ Grand multiparity $\geq 5$} \\
\hline Yes & 2 & 5.4 \\
\hline No & 35 & 94.6 \\
\hline \multicolumn{3}{|l|}{ Prior uterine curettage } \\
\hline Yes & 5 & 13.5 \\
\hline No & 32 & 86.4 \\
\hline \multicolumn{3}{|l|}{ Twin delivery } \\
\hline Yes & 2 & 5.4 \\
\hline No & 35 & 94.6 \\
\hline
\end{tabular}

Mean operative time, estimated blood loss, injury to urinary tract, febrile illness and duration of hospital stay was higher in TAH group as compared to STH group but difference was not statistically significant except for estimated blood loss. Intraoperative hypotension and number of blood transfusions were higher after STH than TAH and all patients of hysterectomy needed ICU care but this trend did not reach statistical significance. Table 7 presents in detail the clinical parameters related to emergency TAH and STH. 14 (38\%) patients developed DIC and in 7 patients it was corrected successfully and 7 patients could not be revived.18 (48.5\%) patients had febrile illnesses, $4(10.8 \%)$ had bladder injury and 1 patient sustained ureteric injury. Neonatal mortality was seen in $56.8 \%$ of cases. 
Table 6: Association of previous cesarean section with placenta accreta and placenta previa.

\begin{tabular}{|llllll|}
\hline Accreta & No cesarean section & 1 cesarean section & 2 cesarean section & 3 cesarean section & P value \\
\hline Yes & $3(25)$ & $9(64)$ & $6(60)$ & $1(100)$ & 0.049 \\
\hline No & $9(75)$ & $5(36)$ & $4(40)$ & $0(0)$ & \\
\hline Previa & & & & & 0.09 \\
\hline Yes & $2(16)$ & $8(66)$ & $6(50)$ & $0(0)$ \\
\hline No & $10(84)$ & $4(34)$ & $6(50)$ & $1(100)$ \\
\hline
\end{tabular}

Table 7: Type of hysterectomy according to indication.

\begin{tabular}{|c|c|c|c|}
\hline Indication & Total hysterectomy & Subtotal hysterectomy & P value \\
\hline Morbidly adherent placenta & $13(68.4)$ & $6(31.6)$ & \multirow{4}{*}{0.09} \\
\hline Atonic PPH & $1(33.3)$ & $2(66.7)$ & \\
\hline Uterine rupture & $6(40)$ & $9(60)$ & \\
\hline Total & $20(54)$ & $17(46)$ & \\
\hline
\end{tabular}

Table 8: Clinical parameters related to type of hysterectomy.

\begin{tabular}{|llll|}
\hline Observation & TAH $(\mathbf{N}=\mathbf{2 0})$ & $\mathbf{S T H}(\mathbf{N}=\mathbf{1 7})$ & P value \\
\hline Operative time (hours), mean (SD) & $3.1 \pm 0.69$ & $2.8 \pm 0.49$ & 0.14 \\
\hline Estimated blood loss (ml), (SD) & $1.74 \pm 0.35$ & $1.4 \pm 0.5$ & 0.02 \\
\hline Blood transfusion $(\mathbf{m l})$, mean $(\mathbf{S D})$ & $2.6 \pm 0.82$ & $3 \pm 1.73$ & 0.36 \\
\hline Intraoperative hypotension, $\mathbf{N}$ & 50 & 53 & 0.9 \\
\hline Injury to the urinary tract, $\mathbf{N}$ & 3 & 1 & 0.9 \\
\hline ICU admission, $\mathbf{N}$ & 100 & 100 & - \\
\hline Febrile illness, $\mathbf{N}$ & 45 & 29.4 & 0.9 \\
\hline Mean hospital stay (days), mean (SD) & $9.4 \pm 3.3$ & $8.8 \pm 3.21$ & 0.58 \\
\hline
\end{tabular}

Table 9: Complication associated with EPH.

\begin{tabular}{|lll|}
\hline Complication & Number & \\
\hline DIC & 14 & 38 \\
\hline Febrile illness & 18 & 48.5 \\
\hline Injury to bladder & 4 & 10.8 \\
\hline Ureteric injury & 1 & 2.7 \\
\hline Maternal mortality & 7 & 19 \\
\hline Neonatal death & 21 & 56.8 \\
\hline
\end{tabular}

\section{DISCUSSION}

PPH is one of the major causes of maternal mortality in India. EPH is lifesaving surgery performed in cases of intractable PPH not controlled by conventional methods.

There is considerable variation in the incidence of PPHrelated hysterectomy in different countries and even among institutions of the same country. It depends on the socioeconomic status of the population, standard of obstetric care, health infrastructure of that area, acceptability of family planning services, varying cesarean delivery rate, availability of other treatment methods.

The overall incidence of EPH at our hospital was 1.1/1000 deliveries which is slightly higher than those of developed countries like United Kingdom and Nordic countries. ${ }^{8,9}$ It is considerably lower than that reported in Nigeria
(5/1000), Pakistan (2.7/1000) and another study from India. $^{10-12}$

In present study, EPH was commonly associated with cesarean section (5.2/1000) than vaginal deliveries (0.04/1000). Previous studies also suggest that EPH is 2-4 times more common following cesarean section than vaginal delivery. ${ }^{13,14}$

In present study, $75 \%$ of women who underwent EPH were primi or second gravida and their age ranged between 2635 years. In present scenario, primary caesarean section rate has increased and over the counter availability of abortifacient drugs and self- medication of these drugs result in increased chances of uterine curettage after incomplete abortion. Previous caesarean section and history of uterine instrumentation are important risk factors for morbidly adherent placenta. Previous studies suggest that advanced maternal age and high parity are also risk factors for EPH. ${ }^{15,16} \mathrm{EPH}$ at an early age, even in primigravida and morbidly adherent placenta as most common indication for EPH in present study, reflect the change in situation.

Indication of EPH has been changed significantly over time and from one region to another. In previous studies uterine atony was the most common indication for hysterectomy. ${ }^{17,18}$ Some studies have reported that 
abnormal placentation is replacing uterine atony as the most common indication for EPH. ${ }^{19,20}$

In our study also morbidly adherent placenta $(51.4 \%)$ was the most common indication for EPH. Second most common indication was rupture of an unscarred uterus $(21.6 \%)$ followed by rupture of scarred uterus $(18.9 \%)$ and atonic uterus $(8.1 \%)$. This could be explained by the increased number of patients who had undergone prior cesarean deliveries $(67.6 \%)$ in our cohort. It has been reported that risk of abnormal placentation and $\mathrm{EPH}$ increases with increasing number of prior cesarean section. $^{21,22} 84.2 \%$ of these cases of placenta accreta and $46.6 \%$ cases of rupture uterus had history of at least one cesarean section in the past.

An increase in cesarean section rate is associated with increased incidence of placenta previa, morbidly adherent placenta and scarred uterus.

The incidence of atonic PPH has reduced comparatively over the decades because of availability of better uterotonic drugs, embolization and improved surgical procedures.In developing countries like ours, rupture of unscarred uterus secondary to obstructed labour and atonic PPH continue to be a predominant indication due to grand multiparity, lack of antenatal care, unsupervised labour at home and delayed patient admission from distant area. ${ }^{23}$

In the present study, total hysterectomy was performed in $54 \%$ of EPH cases. $65 \%$ of these cases were those of morbidly adherent placenta and placenta previa, $30 \%$ were of uterine rupture and $5 \%$ was of uterine atony.

It is often debated whether to perform subtotal or total hysterectomy during EPH. The type of surgery chosen depends on patient condition, indication, skill of operating surgeon and ease of access to cervix. Total hysterectomy is preferred surgical method in cases of placenta previa where active bleeding occurs from the lower uterine segment as the cervical branch of uterine artery may remain intact and due to the potential risk of malignancy developing in cervical stump. ${ }^{24}$

STH is a much faster and technically safer procedure for desperately ill patients and those who may have massive adhesions over the lower uterine segment involving the urinary bladder. Supporters of STH state that it is associated with reduced blood loss, shorter duration of operation, fewer intra and postoperative complications. ${ }^{25}$

Present study did not reveal any statistically significant difference in hysterectomy type with respect to mean operative time, the number of blood transfusions given, the total number of hospitalization days, indications for hysterectomy and other complications as in other reports. ${ }^{26,27}$ Hence, while TAH is a desirable procedure, STH may be a better choice in certain conditions where surgery needs to be completed in a shorter time. ${ }^{28}$
In present study, there were 7 maternal deaths giving a mortality rate of $18.9 \%$ and cause of death was attributed to hemorrhagic shock or disseminated intravascular coagulation secondary to massive blood loss which could not be controlled even after hysterectomy. In previous studies maternal mortality ranges from $3-19.4 \%$ following emergency hysterectomy. ${ }^{17,19,20,29-31}$

This high mortality rate may be related to the characteristics of our hospital as a referral hospital, delay in referral of cases, unplanned emergency situations in which surgery had been performed.

It is evident that maternal deaths can be reduced with availability of blood and blood products, competent surgeon and anesthetist. This also needs improvement in transport services, antenatal care, family planning services and awareness regarding the knowledge of hospital delivery.

We also found high perinatal mortality $56.8 \%$ in present study similar to other studies which reported rates of $37 \%$ to $64 \% .^{32-35}$ This may be due to high number of hysterectomies performed for morbidly adherent placenta at early gestation before 34 weeks in emergency situations and for rupture uterus. Both conditions are known to have adverse effects on perinatal outcome.

\section{Limitations}

Major limitation of the present study was its retrospective nature and recruitment of a small number of cases. Many aspects of peripartum hysterectomy could not be commented upon because of lack of documentation of information.

\section{CONCLUSION}

In present study, morbidly adherent placenta was a prime indication for EPH. The worldwide increase in caesarean section rate may lead to an increased chance of scar dehiscence and morbidly adherent placenta thereby increasing the number of peripartum hysterectomies required in future. Thus there is a need for the institute to take strict measures to reduce caesarean section rate. Vaginal birth after cesarean section should be encouraged. Cesarean section at maternal request should be discouraged. Effective implementation of family planning programme, creating community awareness about the need of seeking early and regular antenatal care, training of staff working in periphery about identification of high risk case and timely referral are urgent need of hour to reduce the incidence of peripartum hysterectomies and life threatening obstetric complications in developing countries.

\author{
Funding: No funding sources \\ Conflict of interest: None declared \\ Ethical approval: The study was approved by the \\ Institutional Ethics Committee
}




\section{REFERENCES}

1. UNICEF. Maternal health-UNICEF's concerted action to increase access to quality maternal health services. 2019. Available at: http://www.unicef.org/india/what-we-do/maternalhealth. Accessed on: 20 June 2020.

2. Park EH, Sachs BP. Postpartum haemorrhage and other problems of third stage. In High Risk Pregnancy - Management Options, James DK, Steer PJ, Weiner CP, Gonik B, eds. W.B. Saunders, Philadelphia, Pa, USA, 2nd edition. 1999;1231-46.

3. Clark SL, Yeh SY, Phelan JP, Bruce S, Paul RH. Emergency hysterectomy for obstetric hemorrhage. Obstet Gynecol. 1984;64:376-80.

4. Chestnut DH, Eden RD, Gall SA, Parker RT. Peripartum hysterectomy: a review of caesarean and postpartum hysterectomy. Obstet Gynecol. 1985;65:365-70.

5. Awan N, Bennett MJ, Walters WA. Emergency peripartum hysterectomy: a 10-year review at the Royal hospital for women, Sydney. Aust N Z J Obstet Gynaecol. 2011;51:210-5.

6. Christopoulos P, Hassiakos D, Tsitoura A, Panoulis K, Papadias K, Vitoratos N. Obstetric hysterectomy: a review of cases over 16 years. J Obstet Gynaecol. 2011;31:139-41.

7. Say L, Souza JP, Pattinson RC. Maternal near miss towards a standard tool for monitoring quality of maternalhealth care. Best Pract Res Clin Obstet Gynaecol. 2009;23(3):287-96.

8. Colmorn LB, Petersen KB, Jakobsson M, Lindqvist PG, Klungsoyr K, Källen K, et al. The nordic obstetric surveillance study: a study of complete uterine rupture, abnormally invasive placenta, peripartum hysterectomy, and severe blood loss at delivery. Acta Obstet Gynecol Scand. 2015;94(7):734-44.

9. Knight M, Kurinczuk JJ, Spark P, Brocklehurst P, Committee UKOSSS. Cesarean delivery and peripartum hysterectomy. Obstet Gynecol. 2008;111(1):97-105.

10. Nwobodo E, Nnadi D. Emergency obstetric hysterectomy in a tertiary hospital in sokoto, Nigeria. Ann Med Health Sci Res. 2012;2(1):37-40.

11. Korejo R, Nasir A, Yasmin H, Bhutta S. Emergency obstetric hysterectomy. J Pak Med Assoc. 2012;62(12):13221325.

12. Juneja SK, Tandon P, Mohan B, Kaushal S. A change in the management of intractable obstetrical hemorrhage over 15 years in a tertiary care center. Int J Appl Basic Med Res. 2014;4(1):17-9.

13. Royal College of Obstetrics and Gynaecology, Postpartum Haemorrhage, Prevention and Management (Guideline 52), RCOG. 2009. Available at: http://www.rcog.org.uk/womens-health/clinicalguidance/prevention-and-management-postpartumhaemorrhage-green-top-52. Accessed on: 20 July 2020 .
14. Stones RW, Paterson CM, Saunders NJ. Risk factors for major obstetric haemorrhage. Eur J Obstetr Gynecol Reprod Biol. 1993;48(1):15-8.

15. Zelop CM, Harlow BL, Frigoletto FD, Safon LE, Saltzman DH. Emergency peripartum hysterectomy. Am J Obstet Gynecol. 1993;168:1443-8.

16. Korejo R, Jafarey SN. Obstetrics hysterectomy - five years' experience at Jinnah Postgraduate Medical Centre, Karachi. J Pak Med Assoc. 1995;45:86-8.

17. Tahmina S, Daniel M, Gunasegaran P. Emergency peripartum hysterectomy: A 14- year experience at a tertiary care centre in india. J Clin Diagn Res.2017;11:8-11.

18. Chawla J, Arora CD, Paul M, Ajmani SN. Emergency obstetric hysterectomy: a retrospective study from a teaching hospital in north India over eight years. Oman Med J. 2015;30(3):181-6.

19. Sharma B, Sikka P, Jain V, Bagga R, Suri V. Peripartum hysterectomy in a tertiary care hospital: Epidemiology and outcomes Improving outcomes for peripartum hysterectomy: Still a long way to go! J Anaesthesio Clin pharmacol. 2017;33:324-8.

20. Agrawal S. Peripartum hysterectomy in a teaching hospital in India. Asian J Med Sci. 2014;4(1):59.

21. Stanco LM, Schrimmer DB, Paul RH, Mischell DR. Emergency peripartum hysterectomy and associated risk factors. Am J Obstet Gynecol. 1993;168:879-83.

22. Miller DA, Chollet JA, Goodwin TM. Clinical risk factors for placenta previa-placenta accreta. Am J Obstet Gynecol. 1997;177:210-4.

23. Marwaha P, Kaur M, Gupta A. Peripartum hysterectomy- a five-year study. J Obstet Gynecol India. 2008;58(6):504-6.

24. Yucel O, Ozdemir I, Yucel N, Somunkiran A. Emergency peripartum hysterectomy: a 9 year review. Arch Gynecol Obstet. 2006;274:84-7.

25. Roopnarinesingh R, Fay L, Mckenna P. A 27 year review of obstetric hysterectomy. J Obstet Gynaecol. 2003;23:252-4.

26. Kastner ES, Figueroa R, Garry D, Maulik D. Emergency peripartum hysterectomy: experience at a community teaching hospital. Obstet Gynecol. 2002;99:971-5.

27. Smith J, Mousa HA. Peripartum hysterectomy for primary postpartum haemorrhage: incidence and maternal morbidity. J Obstet Gynaecol. 2007;27:44-7.

28. Machado LSM. Emergency peripartum hysterectomy: Incidence, indications, risk factors and outcome. $\mathrm{N}$ Am J Med Sci. 2011;3(8):358-61.

29. Ahmad S, Mir I. Emergency peripartum hysterectomy: experience at apex hospital of Kashmir valley. Internet J Gynecol Obstet. 2006;8(2):1-4.

30. Sharma R, Shaheen, Pathak J. Peripartum hysterectomy review of 70 cases. South Asian Federation Obstet Gynecol. 2009;1(2):19-21.

31. Varalakshmi K, Rastogi R, Choudhary N. Study of maternal outcome in emergency peripartum hysterectomy at a tertiary hospital. Int $\mathrm{J}$ Reprod Contracept Obstet Gynecol. 2017;6:5602-8. 
32. Chawla J, Arora CD, Paul M, Ajmani SN. Emergency obstetric hysterectomy: a [6] retrospective study from a teaching hospital in north India over eight years. Oman Med J. 2015;30(3):181-6.

33. Abasiattai AM, Umoiyoho AJ, Utuk NM, InyangEtoh EC, Asuquo OP. Emergency peripartum hysterectomy in a tertiary hospital in southern Nigeria. Pan Afr Med J. 2013;15:60.

34. Korejo R, Nasir A, Yasmin H, Bhutta S. Emergency obstetric hysterectomy. JPMA. 2012;62:1322.
35. Sahu L, Chakravertty B, Panda S. Hysterectomy for Obstetric Emergencies. J Obstet Gynaecol India. 2004;54(1):34-6.

Cite this article as: Khatik N, Pandey A, Yadav SS, Yadav K. Emergency peripartum hysterectomy: a 3 year review at a tertiary care hospital in Vindhya region of India. Int J Reprod Contracept Obstet Gynecol 2020;9:4455-61. 